\title{
Neurobiology of Stroke Recovery
}

\author{
Eddie Kane and Nick S. Ward
}

A stroke occurs somewhere in the world every $2 \mathrm{~s}$ adding up to almost 17 million people each year (Feigin et al. 2014). Stroke is one of the most common causes of disability. Over one million people in the UK are currently living with the consequences of stroke, over one-third of whom are dependent on others for their care. Even though stroke mortality is declining (Lackland et al. 2014), the number of people set to live with the consequences of stroke is set to rise over the next 20 years (Patel et al. 2017; Crichton et al. 2016) with huge personal, societal and economic consequences (Patel et al. 2017). Improvement of recovery and long-term outcomes is therefore an urgent clinical and scientific goal, but success is slow to materialize. Understanding the underlying neurobiology of stroke recovery could speed up ways to help improve outcomes.

Care in the hyperacute and acute period after stroke has improved dramatically over the past two decades, but it is widely accepted that our attention must turn to treatments that actively promote recovery. The key treatments for promoting behavioural recovery in motor, language and cognitive domains after stroke are themselves behavioural treatments (loosely grouped under the headings physiotherapy, occupational therapy, speech and language therapy, neuropsychology) that we can consider inputs (into the brain). The consequent change in behaviour can be

\author{
E. Kane \\ Department of Clinical and Motor Neuroscience, \\ UCL Queen Square Institute of Neurology, London, UK \\ e-mail: edward.kane.18@ucl.ac.uk \\ N. S. Ward $(\bowtie)$ \\ Department of Clinical and Motor Neuroscience, \\ UCL Queen Square Institute of Neurology, London, UK
}

The National Hospital for Neurology and Neurosurgery, Queen Square, London, UK

UCL Partners Centre for Neurorehabilitation,

UCL Institute of Neurology, Queen Square, London, UK

e-mail: n.ward@ucl.ac.uk 
considered an output (from the brain). It is becoming more accepted that the amount of input (and probably the quality) affects the output (Lohse et al. 2014). For example, significantly higher doses of good quality upper-limb rehabilitation have large beneficial effects, even in chronic stroke (McCabe et al. 2015; Daly et al. 2019; Ward et al. 2019). The input-output relationship can be modulated by brain states, and we think of these states as enhancing the potential for experience dependent plasticity, and it is these brain states that will be the focus of this review.

The early post-stroke phase has been described as a period of 'spontaneous biological recovery' (Krakauer et al. 2012). Spontaneous biological recovery is a behavioural response to underlying biological events occurring in the first few weeks and months after stroke attributable to enhanced post-stroke plasticity mechanisms. Recovery is rapid, occurs at the level of impairment and generalizes beyond the tasks that are used in post-stroke training, which is different to improvements seen in the chronic phase of stroke (Zeiler and Krakauer 2013). This leads to the hypothesis that behavioural interventions will have a quantitative and qualitatively greater effect if delivered in this period compared to outside of this period. This raises two major challenges for the field of stroke rehabilitation. The first is to determine what is the correct form of behavioural training (the input) to take advantage of this critical period. This is not trivial, as has been discussed elsewhere (Krakauer and Carmichael 2017). The second challenge is how (and importantly, when) to augment the biological mechanisms of post-stroke plasticity to enhance or prolong the effects of behavioural training in patients after a stroke. It is important to note that although work in preclinical animal models has been pivotal in highlighting the biological basis of recovery, few benefits have been seen for human stroke patients. This is likely to require the development of human biomarkers to move this field of research into the human arena (Ward 2017). Here, we define biomarkers using the Stroke Recovery and Rehabilitation Roundtable criteria-Indicators of disease state that can be used clinically as a measure reflecting underlying molecular or cellular processes that might be difficult to measure directly in humans, and can be used to predict recovery or treatment response (Bernhardt et al. 2016).

One of the first studies providing behavioural evidence of this post-stroke critical period for recovery-related training was provided by Biernaskie and colleagues (Biernaskie et al. 2004) who found that rats commencing training of the affected forelimb starting at 30 days post-stroke exhibited the same level of improvement as those who received no training. However, those whose treatment commenced at 5-14 days post-stroke had better recoveries. This suggests that there is a time limited effect of the lesion itself on the brain's potential for plasticity. This was supported by Zeiler and colleagues (Zeiler et al. 2015) who showed that intensive motor training of a mouse commenced 7 days after stroke was not able to promote full recovery. However, when the same animal was given a second stroke and training was commenced 2 days later then recovery was substantially enhanced. These results suggest that focal brain damage results in a series of biological events that, when combined with appropriate behavioural training (Krakauer et al. 2012), can support recovery. 


\section{$1 \quad$ Changes in Structural Plasticity After Stroke}

A substantial amount of work has been undertaken in animal models to define the molecular and cellular processes that occur after stroke. These studies are well described elsewhere (Krakauer and Carmichael 2017; Murphy and Corbett 2009; Carmichael 2016; Cramer and Chopp 2000; Wieloch and Nikolich 2006) and by the nature of the experimental model concern largely sensorimotor recovery rather than other domains that are important in human stroke. Nevertheless, these studies are instructive if we are interested in the capacity of the central nervous system to support recovery. Briefly, focal ischaemic brain damage leads to cell death followed by secondary damage, then to the elements important for recovery, namely regeneration and (partial) repair (Krakauer and Carmichael 2017; Wieloch and Nikolich 2006). The basic elements of neural repair that can be seen in animal models of stroke change over time and include axonal sprouting, dendritic branching, synaptogenesis, neurogenesis and gliogenesis and all can be enhanced in the early poststroke period. These post-stroke changes also have spatial characteristics, seeming to occur in brain regions connected to the damaged area, including peri-infarct, ipsilesional and contralesional brain and spinal cord networks. Not all these biological responses to injury are necessarily beneficial. For example, only axonal sprouting that links functionally related brain areas is consistently associated with improved post-stroke outcomes (Carmichael et al. 2016). The precise temporal and spatial ordering of the biological events that occur after stroke are likely to be governed by alterations in gene expression and it is often suggested that the biological environment of the post-stroke brain resemble that of the developing brain, and that 'recovery recapitulates ontogeny' (Cramer and Chopp 2000). Recent work however points to this being an over simplification and that in reality there is a unique regenerative molecular program at work with a clear distinction between regenerative and developmental transcriptomes ( $\mathrm{Li}$ et al. 2010). Furthermore, expression of the regenerative transcriptome is strongly influenced by age at stroke onset, with younger animals expressing growth-promoting molecules earlier and growthinhibiting molecules later than older animals (Li and Carmichael 2006). Definitive evidence of these restorative processes in humans is scarce, but markers suggestive of neurogenesis (Jin et al. 2006), gliogenesis (Sanin et al. 2013) and axonal sprouting (Jin et al. 2006) have been found in human post-stroke perilesional brain tissue. Consequently, the occurrence of similar biological responses to brain injury in both animals and humans seems probable.

There are a number of approaches to developing pharmacological therapies that aim to promote structural plasticity after stroke in order to enhance outcomes. Firstly, there is successful preclinical work to block extracellular inhibitory signals that counteract regeneration using axonal growth inhibitors (Wahl and Schwab 2014; Benowitz and Carmichael 2010). For example, myelin-associated proteins such as NogoA, myelin-associated glycoprotein (MAG) and myelin-associated oligodendrocyte basic protein have been shown to block neuronal regeneration. AntiNogoA strategies have been used in preclinical models both of stroke and of spinal cord injury and can lead to improved recovery profiles, probably through both 
vascular and neural repair mechanisms (Rust et al. 2019). In terms of structural changes to the central nervous system in response to anti-NogoA, axonal sprouting is often seen across the midline, either at the level of brain stem or spinal cord. Lindau and colleagues (Lindau et al. 2014) found that in rats undergoing sensorimotor cortex ablation but then treated with anti-NogoA antibody, intact corticospinal tract had extensively sprouted across the midline into the denervated spinal hemicord, which led to a somatotopic anatomical and functional side switch in the projection of adult corticospinal neurons. The safety of anti-NogoA antibodies has been tested in patients with spinal cord injury (Wahl and Schwab 2014) and amyotrophic lateral sclerosis (Meininger et al. 2014), and anti-MAG has been tested in patients with stroke (Cramer et al. 2013). Many of the antibody molecules are large and it is not clear how well they cross the blood-brain barrier after stroke (when it is damaged). Alternative ways of achieving the same response, through genetic manipulation for example (Rust et al. 2019), are being explored.

Other candidate molecules that inhibit the axonal growth cone, e.g. semaphorins and ephrins, and so block neuronal regeneration are also being investigated. After stroke damage, ephrin-A5 is induced in astrocytes in peri-infarct cortex, which leads to inhibition of axonal sprouting. When ephrin-A5 signalling is blocked, motor training is more liable to promote recovery (Overman et al. 2012).

Axon growth can also be blocked by perineuronal nets (PNNs), a property mediated by chondroitin sulphate proteoglycans. After ischaemic cortical damage, the density of PNNs is reduced in peri-infarct cortex, likely representing one of the mechanisms of spontaneous biological recovery (Allred et al. 2005). This biological environment can be recreated by the enzyme chondroitinase $\mathrm{ABC}$, which can reverse blocking of axonal growth, thereby reinstating critical period plasticity via the inactivation of chondroitin sulphate proteoglycans and therefore PNNs (Pizzorusso et al. 2002). In a rat model of stroke, chondroitinase ABC helped restore motor function after both acute and delayed administration (Gherardini et al. 2015).

Rather than blocking axonal growth inhibitors, the naturally occurring purine nucleoside inosine has been reported to enhance axon growth and improve outcomes in a preclinical model of stroke. Inosine promotes axonal collateral sprouting into areas that have lost their normal innervation, such as the corticospinal tract after stroke (Zai et al. 2009) or hippocampus after experimental traumatic brain injury (Dachir et al. 2014). Furthermore, inosine can augment the effects of anti-NogoA antibody to restore skilled forelimb use after stroke (Zai et al. 2011).

In other classes of drugs, phosphodiesterase (PDE) inhibitors can prevent the degradation of cyclic nucleotides (cAMP and cGMP) which amongst other things promote axonal sprouting. There has been interest in whether drugs such as sildenafil (PDE5 inhibitor) or cilostazol (PDE3 inhibitor) can improve outcomes after stroke (Munshi and Das 2017), but their translation into use in human stroke remains a long way off.

Increasingly, interest has been shown in the use of stem cell therapy to promote recovery after stroke (Kalladka and Muir 2016). The two main lines of stem cell therapies are endogenous (promoting the production of existing neural stem cells) or exogenous (transplanted from another source) (Azad et al. 2016). Over the past 
few years, research has explored how to reprogram adult human somatic cells to induced pluripotent stem cells thereby producing patient-specific cells for autologous transplantation (Tornero et al. 2013). Rather than restoring lost tissue, stem cells could act as stimulants for trophic factors and modulators of immunological and inflammatory changes after stroke. Trials of exogenous cells in humans have proved safe, and claims have been made for improved clinical outcomes in patients with chronic stroke (Steinberg et al. 2016; Kalladka et al. 2016).

The timing of administration of growth-promoting compounds, both in relation to the initial stroke damage and to the behavioural training itself, will clearly have a major effect on the therapeutic capacity. Whether training is delivered at the same time as growth-promoting molecules or sequentially could influence the type of sprouting that occurs and, consequently, whether behaviour is helped or hindered (Wahl et al. 2014). In addition, the effect that post-stroke behaviour can have on regenerative processes themselves is important to understand. For example, early compensatory use of the contralesional forelimb impairs recovery of the affected limb (Allred et al. 2005), possibly through aberrant synaptogenesis in the perilesional cortex (Kim et al. 2015). Any behaviour, if overtrained, will take advantage of the increased post-stroke potential for experience-dependent plasticity, and so abnormal or compensatory patterns of behaviour can become learned. Once again, this finding highlights the need for an appropriate form of behavioural training that can take advantage of any spontaneous or therapeutically enhanced potential for plasticity.

As well as asking 'when' treatment should be administered and 'where' is probably an equally important question. Most of the compounds discussed have been administered via intravenous or intrathecal routes, but accurate spatial and temporal delivery might both be necessary to achieve the desired outcomes. Advances made in the last few years in tissue engineering (Nih et al. 2016; Memanishvili et al. 2016) and optogenetics (Pendharkar et al. 2016) provide potential methods for precisely delivering regenerative molecules to functionally relevant brain regions. In this case, it might then be preferable to take advantage of the possibility of delivering brain region-specific stem cell therapies (cells that have cortical or basal ganglialike phenotypes). Given the importance of white matter damage in human stroke (white matter constitutes over $50 \%$ of brain volume in humans in comparison to less than $10 \%$ in rodents), it is even possible that replacing lost glia is a more successful strategy in some cases, than replacing lost neurons (Tornero et al. 2013; Kokaia et al. 2017).

\section{Changes in Functional Plasticity After Stroke}

So far, we have concentrated on post-stroke changes in brain structure and how these processes may be therapeutically altered. In addition to these structural changes, focal brain damage also results in alterations in neuronal excitability (Carmichael 2012). Immediately after stroke, signalling by the excitatory neurotransmitter glutamate is excitotoxic and contributes to cell death, whereas 
signalling by the inhibitory neurotransmitter GABA can counteract this toxicity through cell hyperpolarization (Lai et al. 2014). In the mouse model, the beneficial and detrimental effects of GABA and glutamate signalling seem to reverse after about 3 days post-stroke (Clarkson et al. 2010). This is of potentially great interest, since changes to the cortical excitatory-inhibitory balance have long been known to influence the potential for experience-dependent plasticity and can reopen critical periods of plasticity in the adult brain (Bavelier et al. 2010). The link between changes in so called 'functional plasticity' is that reduced inhibitory tone can lead to facilitation of downstream changes in neuronal structure (Chen et al. 2011). One possibility then is that the altered levels of neuronal activity that result from a change in excitability regulate neurogenesis and the activity of growth factors (such as brain derived neurotrophic factor; BDNF) through epigenetic mechanisms (Felling and Song 2015). Reduced cortical inhibitory mechanisms can also lead to expanded and less specific receptive fields (Alia et al. 2016; Winship and Murphy 2008), enhanced long-term potentiation (Hagemann et al. 1998) and remapping of sensorimotor functions to surviving cortex (Takatsuru et al. 2009) in both hemispheres (Que et al. 1999), all of which is potentially useful when functional reorganization of residual post-stroke brain structures is important for recovery of normal function. Stroke-induced changes in the inhibitory-excitatory balance in surviving brain regions (particularly cortex) could, therefore, be a key event that sets other restorative mechanisms in motion.

One idea is that attenuation of neuronal activity in brain regions connected to the damaged area after stroke might be reversed by a homeostatic increase in neuronal excitability, a process that can last at least several weeks (Murphy and Corbett 2009). Levels of neuronal excitability are determined by the balance in activity between GABA and glutamate, both of which are known to be altered after stroke (Carmichael 2012). For example, enhanced glutamate signalling through AMPA receptors, the major excitatory signalling system in the adult brain, is associated with improved recovery in stroke models due to downstream induction of BDNF (Clarkson et al. 2011). GABA $\mathrm{A}_{\mathrm{A}}$ receptors, on the other hand, are dowregulated (Que et al. 1999; Schiene et al. 1996), and the density of a number of inhibitory interneurons is reduced after focal brain damage (Alia et al. 2016; Zeiler et al. 2013), suggesting a reduction in in phasic (synaptic) inhibition in the first few weeks after injury (Neumann-Haefelin et al. 1995) to increase the likelihood of long-term potentiation (Hagemann et al. 1998). Both increased glutamatergic signalling and reduced phasic GABAergic signalling would be consistent with the idea of a homeostatic restitution of neuronal activity (Murphy and Corbett 2009). However, other work has focussed on tonic GABAergic inhibition, suggesting that there is a dominant increase in perilesional tonic inhibition, mediated by extrasynaptic $\mathrm{GABA}_{\mathrm{A}}$ receptors (Clarkson et al. 2010; Lake et al. 2015). Reversing this tonic inhibition (using an $\alpha 5$ subunit that contained an extrasynaptic $\mathrm{GABA}_{\mathrm{A}}$-receptor inverse agonist) improved motor outcomes in both mouse (Tornero et al. 2013) and rat (Lai et al. 2014) models of stroke. The increase in tonic inhibitory signalling can persist for more than 1 month (Carmichael 2012) making this therapeutic window attractive. 
The interactions between excitatory pyramidal cells and numerous inhibitory interneurons in the cortex are clearly complex and become more complex after stroke (Clarkson 2012). In addition, prolonged ischaemia affects different cell types unequally (Sakuma et al. 2008) and causes alterations in the distribution of receptor subtypes (Kharlamov et al. 2008). Nevertheless, the weight of evidence from animal studies to date suggests that spontaneous biological recovery is either augmented by a homeostatic restitution of cortical activity secondary to reduced phasic GABAergic inhibitory signalling or blocked by excessive tonic GABAergic inhibitory signalling. Beyond the hyperacute period (up to 3 days post-stroke), what follows at a cellular level suggests that alterations in cortical inhibitory and excitatory mechanisms are important in determining the potential for plasticity and downstream structural changes that support recovery. Consequently, components of these inhibitory and excitatory mechanisms represent exciting and novel therapeutic targets for enhancing behavioural training after stroke.

The mechanisms responsible for the alterations in cortical excitatory-inhibitory balance that underlie changes in post-stroke functional plasticity are amenable to pharmacological and non-pharmacological manipulation. There is much interest in the use of selective serotonin reuptake inhibitors (SSRIs) for promoting recovery after stroke. SSRIs can influence structural plasticity, but there is compelling evidence to support a plasticity-modifying effect mediated through the GABAergic system. Chronic doses of fluoxetine can reinstate critical period plasticity in adult rats through a reduction of extracellular levels of GABA and an increase in BDNF expression (Maya Vetencourt et al. 2008). Furthermore, in a mouse model of stroke, $\mathrm{Ng}$ and colleagues ( $\mathrm{Ng}$ et al. 2015) showed that fluoxetine treatment prolonged (but did not reinstate) the critical period of post-stroke plasticity through the reduction of inhibitory interneuron expression in intact cortex ( $\mathrm{Ng}$ et al. 2015). Serotonin can have inhibitory (via $5 \mathrm{HT}_{1 \mathrm{~A}}$ receptors) or facilitatory (via $5 \mathrm{HT}_{2 \mathrm{~A}}$ receptors) effects on pyramidal cells, but most fast-spiking inhibitory interneurons are inhibited by serotonin through $5 \mathrm{HT}_{1 \mathrm{~A}}$ receptors (Puig et al. 2010). In the cortex, chronic fluoxetine administration induces a reduction in layer II-III inhibitory interneuron activity which facilitates experience-driven structural dendritic remodelling (Chen et al. 2011). A separate study in human primary motor cortex slices demonstrated that fluoxetine-induced reduction of inhibitory tone comes about through suppression of layer II-III monosynaptic excitatory connections from pyramidal cells to inhibitory interneurons, which leaves the monosynaptic output of GABAergic cells unaffected (Komlósi et al. 2012). This layer-specific effect of fluoxetine is interesting in the context of work that demonstrates that early post-stroke 'enriched rehabilitation' is more effective than environmental enrichment or reach training alone as a result of the enhancement of use-dependent plasticity in peri-infarct layer II-III cortex (Clarke et al. 2014). One idea is that fluoxetine (and other pharmacotherapies) might influence training effects by replicating the biological effects of enriched environments.

Fluoxetine has been well studied in human stroke patients. The fluoxetine for motor recovery after acute ischemic stroke (FLAME) study in which $20 \mathrm{mg}$ fluoxetine daily, started 5-10 days after ischaemic stroke and continued for 3 months, 
enhanced upper-limb motor recovery (Chollet et al. 2011). However, the larger FOCUS study did not show that fluoxetine had an effect on the modified Rankin Scale (FOCUS Trial Collaboration 2019). However, we know that changing the potential for plasticity still requires the appropriate behavioural intervention to take advantage of this new brain state. In FOCUS, no attempt was made to control for or measure the amount of rehabilitation patients received, which makes the results difficult to interpret.

Another approach might be to target the proposed increase in perilesional tonic inhibition. Tonic inhibition can be reversed by antagonists or inverse agonists of the $\alpha 5$-subunit-containing extrasynaptic $\mathrm{GABA}_{\mathrm{A}}$ receptor, and compounds for use in humans are currently available and under investigation. Zolpidem is an interesting pharmacological agent that binds with high affinity to $\alpha 1$-containing $\mathrm{GABA}_{\mathrm{A}}$ receptors through which it mediates sedative and hypnotic effects. However, zolpidem can also influence tonic inhibition through $\alpha 5$-containing $\mathrm{GABA}_{\mathrm{A}}$ receptors in a dose-dependent manner, such that low levels of the drug augment tonic inhibition and high levels reduce it (Prokic et al. 2015). Zolpidem can improve recovery in a mouse model of stroke (Hiu et al. 2015) and has been reported to mediate interesting effects such as the temporary reversal of deficits in language, cognitive and motor function in single patient cases with stroke (Cohen et al. 2004; Hall et al. 2010). However, given the uncertainty over how zolpidem works, the mechanism of recovery in these individuals remains unclear.

The most studied therapeutic option for promoting recovery after stroke is likely to be non-invasive brain stimulation (NIBS). Several systematic reviews suggest that NIBS is able to enhance the effects of behavioural training to a small degree (Hsu et al. 2012; Kang et al. 2015). In a mouse model, direct current stimulation to the brain appeared to augment synaptic plasticity through BDNF dependent mechanisms (Fritsch et al. 2010). However, in human studies, it is not clear how much or how accurately electrical current is delivered to target brain regions, and consequently results are inconsistent and potential mechanisms poorly understood (Bonaiuto and Bestmann 2015; de Berker et al. 2013).

\section{Conclusion Regarding the Neurobiology of Stroke Recovery}

The rationale for understanding how to optimize the post-stroke brain environment is to maximize the effect of behavioural training — which can take the form of physical, cognitive or speech therapy. The presence of a critical period of plasticity mandates for the delivery of high dose and high intensity behavioural training during this window of opportunity to maximize recovery of function by minimizing impairment (Zeiler and Krakauer 2013). Whilst this idea is strongly supported in animal models as already discussed (Biernaskie et al. 2004; Zeiler et al. 2015), there is as yet no direct evidence of this in human stroke patients. Targeting the mechanisms that underlie early spontaneous biological recovery in humans represents the mostpromising path to dramatically improve patients' outcomes (Zeiler and Krakauer 
2013) and should be prioritized. The limits of what is possible in stroke recovery have not yet been explored, especially if the delivery of high doses of behavioural therapy in post-acute or reopened critical periods of plasticity becomes possible.

\section{$4 \quad$ Take Home Message for Clinical Practice in Stroke Rehabilitation}

This chapter on the neurobiology of stroke recovery portrays the state of the art in research on the structural and functional mechanisms of recovery after stroke. It provides scientific reasoning on how clinical interventions in stroke rehabilitation might work and where potentials for future research in stroke recovery and rehabilitation are seen from a neuroscience perspective. It does, however, not provide clinical evidence for stroke rehabilitation, and hence it is not possible to link clinical practice recommendations directly to this type of reasoning. This information will be given in the remainder of the chapters in this book.

As far as the neuroscience perspective goes, some general take-home messages are nevertheless worthwhile to portray on the basis of the overview given.

Alterations of body functions after acquired brain damage such as motor, perceptual, language or cognitive dysfunctions are results of network activities that are affected by structural brain damage. Complex changes in neural excitability and structural changes that occur over an extended period after brain damage will eventually determine the extent of functional recovery achieved by an individual. These processes can be influenced by rehabilitation treatment most likely if it is based on targeted training of high enough intensity and specificity for the affected brain networks and hence dysfunctions. In addition, the processes related to functional recovery can theoretically be modulated by non-invasive brain stimulation, medication and stem cell therapy as outlined above. It is important to keep in mind that these are not completely independent mechanisms. Rather to consider their (partial) contribution and integration into the complex processes of recovery are conceptually appropriate. Whilst the potential for rehabilitation-mediated recovery seems to be biggest early after stroke and needs to be supported by rehabilitation therapy, strategies to promote recovery in later stages after stroke also need to be entertained as focus on its own.

Declaration The authors declare no competing interests.

\section{References}

Alia C et al (2016) Reducing GABAA-mediated inhibition improves forelimb motor function after focal cortical stroke in mice. Sci Rep 6:37823

Allred RP, Maldonado MA, Hsu And JE, Jones TA (2005) Training the 'less-affected' forelimb after unilateral cortical infarcts interferes with functional recovery of the impaired forelimb in rats. Restor Neurol Neurosci 23:297-302

Azad TD, Veeravagu A, Steinberg GK (2016) Neurorestoration after stroke. Neurosurg Focus 40:E2 
Bavelier D, Levi DM, Li RW, Dan Y, Hensch TK (2010) Removing brakes on adult brain plasticity: from molecular to behavioral interventions. J Neurosci 30:14964-14971

Benowitz LI, Carmichael ST (2010) Promoting axonal rewiring to improve outcome after stroke. Neurobiol Dis 37:259

Bernhardt J et al (2016) Moving rehabilitation research forward: developing consensus statements for rehabilitation and recovery research. Int J Stroke 11:454-458

Biernaskie J, Chernenko G, Corbett D (2004) Efficacy of rehabilitative experience declines with time after focal ischemic brain injury. J Neurosci 24:1245-1254

Bonaiuto JJ, Bestmann S (2015) Understanding the nonlinear physiological and behavioral effects of tDCS through computational neurostimulation. Prog Brain Res 222: $75-103$

Carmichael ST (2012) Brain excitability in stroke: the yin and yang of stroke progression. Arch Neurol 69:161-167

Carmichael ST (2016) Emergent properties of neural repair: elemental biology to therapeutic concepts. Ann Neurol 79:895-906

Carmichael ST, Kathirvelu B, Schweppe CA, Nie EH (2016) Molecular, cellular and functional events in axonal sprouting after stroke. Exp Neurol 287:384. https://doi.org/10.1016/j. expneurol.2016.02.007

Chen JL et al (2011) Structural basis for the role of inhibition in facilitating adult brain plasticity. Nat Neurosci 14:587-594

Chollet $\mathrm{F}$ et al (2011) Fluoxetine for motor recovery after acute ischaemic stroke (FLAME): a randomised placebo-controlled trial. Lancet Neurol 10:123-130

Clarke J, Langdon KD, Corbett D (2014) Early poststroke experience differentially alters periinfarct layer II and III cortex. J Cereb Blood Flow Metab 34:630-637

Clarkson AN (2012) Perisynaptic GABA receptors the overzealous protector. Adv Pharm Sci 2012(708428): 1

Clarkson AN, Huang BS, Macisaac SE, Mody I, Carmichael ST (2010) Reducing excessive GABA-mediated tonic inhibition promotes functional recovery after stroke. Nature 468:

305-309

Clarkson AN et al (2011) AMPA receptor-induced local brain-derived neurotrophic factor signaling mediates motor recovery after stroke. J Neurosci 31:3766-3775

Cohen L, Chaaban B, Habert M-O (2004) Transient improvement of aphasia with zolpidem. N Engl J Med 350:949-950

Cramer SC, Chopp M (2000) Recovery recapitulates ontogeny. Trends Neurosci 23:265-271

Cramer SC et al (2013) Safety, pharmacokinetics, and pharmacodynamics of escalating repeat doses of GSK249320 in patients with stroke. Stroke J Cereb Circ 44:1337-1342

Crichton SL, Bray BD, McKevitt C, Rudd AG, Wolfe CDA (2016) Patient outcomes up to 15 years after stroke: survival, disability, quality of life, cognition and mental health. J Neurol Neurosurg Psychiatry 87:1091-1098

Dachir $S$ et al (2014) Inosine improves functional recovery after experimental traumatic brain injury. Brain Res 1555:78-88

Daly JJ et al (2019) Long-dose intensive therapy is necessary for strong, clinically significant, upper limb functional gains and retained gains in severe/moderate chronic stroke. Neurorehabil Neural Repair 33(7):523-537. https://doi.org/10.1177/1545968319846120

de Berker AO, Bikson M, Bestmann S (2013) Predicting the behavioral impact of transcranial direct current stimulation: issues and limitations. Front Hum Neurosci 7:613

Feigin VL et al (2014) Global and regional burden of stroke during 1990-2010: findings from the global burden of disease study 2010. Lancet 383:245-254

Felling RJ, Song H (2015) Epigenetic mechanisms of neuroplasticity and the implications for stroke recovery. Exp Neurol 268:37-45

FOCUS Trial Collaboration (2019) Effects of fluoxetine on functional outcomes after acute stroke (FOCUS): a pragmatic, double-blind, randomised, controlled trial. Lancet 393:265-274

Fritsch B et al (2010) Direct current stimulation promotes BDNF-dependent synaptic plasticity: potential implications for motor learning. Neuron 66:198-204 
Gherardini L, Gennaro M, Pizzorusso T (2015) Perilesional treatment with chondroitinase $\mathrm{ABC}$ and motor training promote functional recovery after stroke in rats. Cereb Cortex 1991(25):202-212

Hagemann G, Redecker C, Neumann-Haefelin T, Freund HJ, Witte OW (1998) Increased longterm potentiation in the surround of experimentally induced focal cortical infarction. Ann Neurol 44:255-258

Hall SD et al (2010) GABA(a) alpha-1 subunit mediated desynchronization of elevated low frequency oscillations alleviates specific dysfunction in stroke-a case report. Clin Neurophysiol 121:549-555

Hiu T et al (2015) Enhanced phasic GABA inhibition during the repair phase of stroke: a novel therapeutic target. Brain 139(Pt 2):468-480. https://doi.org/10.1093/brain/awv360

Hsu W-Y, Cheng C-H, Liao K-K, Lee I-H, Lin Y-Y (2012) Effects of repetitive transcranial magnetic stimulation on motor functions in patients with stroke: a meta-analysis. Stroke J Cereb Circ 43:1849-1857

Jin K et al (2006) Evidence for stroke-induced neurogenesis in the human brain. Proc Natl Acad Sci U S A 103:13198-13202

Kalladka D, Muir KW (2016) Where are we in clinical applications of stem cells in ischaemic stroke? Adv Clin Neurosci Rehabil 16:9-12

Kalladka D et al (2016) Human neural stem cells in patients with chronic ischaemic stroke (PISCES): a phase 1, first-in-man study. Lancet 388:787-796

Kang N, Summers JJ, Cauraugh JH (2015) Transcranial direct current stimulation facilitates motor learning post-stroke: a systematic review and meta-analysis. J Neurol Neurosurg Psychiatry 87:345. https://doi.org/10.1136/jnnp-2015-311242

Kharlamov EA, Downey KL, Jukkola PI, Grayson DR, Kelly KM (2008) Expression of GABA a receptor alpha1 subunit mRNA and protein in rat neocortex following photothrombotic infarction. Brain Res 1210:29-38

Kim SY et al (2015) Experience with the 'good' limb induces aberrant synaptic plasticity in the perilesion cortex after stroke. J Neurosci 35:8604-8610

Kokaia Z, Tornero D, Lindvall O (2017) Transplantation of reprogrammed neurons for improved recovery after stroke. Prog Brain Res 231:245-263

Komlósi $\mathrm{G}$ et al (2012) Fluoxetine (prozac) and serotonin act on excitatory synaptic transmission to suppress single layer $2 / 3$ pyramidal neuron-triggered cell assemblies in the human prefrontal cortex. J Neurosci 32:16369-16378

Krakauer JW, Carmichael ST (2017) Broken movement: the neurobiology of motor recovery after stroke. MIT, Cambridge, MA

Krakauer JW, Carmichael ST, Corbett D, Wittenberg GF (2012) Getting neurorehabilitation right: what can be learned from animal models? Neurorehabil Neural Repair 26:923-931

Lackland DT et al (2014) Factors influencing the decline in stroke mortality: a statement from the American Heart Association/American Stroke Association. Stroke J Cereb Circ 45:315-353

Lai TW, Zhang S, Wang YT (2014) Excitotoxicity and stroke: identifying novel targets for neuroprotection. Prog Neurobiol 115:157-188

Lake EMR et al (2015) The effects of delayed reduction of tonic inhibition on ischemic lesion and sensorimotor function. J Cereb Blood Flow Metab 35:1601. https://doi.org/10.1038/ jcbfm.2015.86

Li S, Carmichael ST (2006) Growth-associated gene and protein expression in the region of axonal sprouting in the aged brain after stroke. Neurobiol Dis 23:362-373

Li S et al (2010) An age-related sprouting transcriptome provides molecular control of axonal sprouting after stroke. Nat Neurosci 13:1496-1504

Lindau NT et al (2014) Rewiring of the corticospinal tract in the adult rat after unilateral stroke and anti-Nogo-a therapy. Brain J Neurol 137:739-756

Lohse KR, Lang CE, Boyd LA (2014) Is more better? Using metadata to explore dose-response relationships in stroke rehabilitation. Stroke J Cereb Circ 45:2053-2058

Maya Vetencourt JF et al (2008) The antidepressant fluoxetine restores plasticity in the adult visual cortex. Science 320:385-388 
McCabe J, Monkiewicz M, Holcomb J, Pundik S, Daly JJ (2015) Comparison of robotics, functional electrical stimulation, and motor learning methods for treatment of persistent upper extremity dysfunction after stroke: a randomized controlled trial. Arch Phys Med Rehabil 96:981-990

Meininger V et al (2014) Safety, pharmacokinetic, and functional effects of the nogo-a monoclonal antibody in amyotrophic lateral sclerosis: a randomized, first-in-human clinical trial. PLoS One 9:e97803

Memanishvili T et al (2016) Generation of cortical neurons from human induced-pluripotent stem cells by biodegradable polymeric microspheres loaded with priming factors. Biomed Mater Bristol Engl 11:025011

Munshi A, Das S (2017) Genetic understanding of stroke treatment: potential role for phosphodiesterase inhibitors. Adv Neurobiol 17:445-461

Murphy TH, Corbett D (2009) Plasticity during stroke recovery: from synapse to behaviour. Nat Rev Neurosci 10:861-872

Neumann-Haefelin T, Hagemann G, Witte OW (1995) Cellular correlates of neuronal hyperexcitability in the vicinity of photochemically induced cortical infarcts in rats in vitro. Neurosci Lett 193:101-104

$\mathrm{Ng} \mathrm{KL}$ et al (2015) Fluoxetine maintains a state of heightened responsiveness to motor training early after stroke in a mouse model. Stroke J Cereb Circ 46:2951-2960

Nih LR, Carmichael ST, Segura T (2016) Hydrogels for brain repair after stroke: an emerging treatment option. Curr Opin Biotechnol 40:155-163

Overman JJ et al (2012) A role for ephrin-A5 in axonal sprouting, recovery, and activity-dependent plasticity after stroke. Proc Natl Acad Sci U S A 109:E2230-E2239

Patel A et al (2017) Executive summary part 2: burden of stroke in the next 20 years and potential returns from increased spending on research. https://www.stroke.org.uk/sites/default/files/ costs_of_stroke_in_the_uk_report_-executive_summary_part_2.pdf (The Stroke Association). Accessed 7th September 2020

Pendharkar AV et al (2016) Optogenetic modulation in stroke recovery. Neurosurg Focus 40:E6

Pizzorusso T et al (2002) Reactivation of ocular dominance plasticity in the adult visual cortex. Science 298:1248-1251

Prokic EJ et al (2015) Cortical oscillatory dynamics and benzodiazepine-site modulation of tonic inhibition in fast spiking interneurons. Neuropharmacology 95:192-205

Puig MV, Watakabe A, Ushimaru M, Yamamori T, Kawaguchi Y (2010) Serotonin modulates fastspiking interneuron and synchronous activity in the rat prefrontal cortex through 5-HT1A and 5-HT2A receptors. J Neurosci 30:2211-2222

Que M et al (1999) Changes in GABA(a) and GABA(B) receptor binding following cortical photothrombosis: a quantitative receptor autoradiographic study. Neuroscience 93:1233-1240

Rust R et al (2019) Nogo-a targeted therapy promotes vascular repair and functional recovery following stroke. Proc Natl Acad Sci U S A 116:14270-14279

Sakuma M, Hyakawa N, Kato H, Araki T (2008) Time dependent changes of striatal interneurons after focal cerebral ischemia in rats. J Neural Transm 1996(115):413-422

Sanin V, Heeß C, Kretzschmar HA, Schüller U (2013) Recruitment of neural precursor cells from circumventricular organs of patients with cerebral ischaemia. Neuropathol Appl Neurobiol 39:510-518

Schiene K et al (1996) Neuronal hyperexcitability and reduction of GABAA-receptor expression in the surround of cerebral photothrombosis. J Cereb Blood Flow Metab 16:906-914

Steinberg GK et al (2016) Clinical outcomes of transplanted modified bone marrow-derived Mesenchymal stem cells in stroke: a phase 1/2a study. Stroke J Cereb Circ 47:1817-1824

Takatsuru $Y$ et al (2009) Neuronal circuit remodeling in the contralateral cortical hemisphere during functional recovery from cerebral infarction. J Neurosci 29:10081-10086

Tornero D et al (2013) Human induced pluripotent stem cell-derived cortical neurons integrate in stroke-injured cortex and improve functional recovery. Brain J Neurol 136:3561-3577

Wahl A-S, Schwab ME (2014) Finding an optimal rehabilitation paradigm after stroke: enhancing fiber growth and training of the brain at the right moment. Front Hum Neurosci 8:381 
Wahl AS et al (2014) Neuronal repair. Asynchronous therapy restores motor control by rewiring of the rat corticospinal tract after stroke. Science 344:1250-1255

Ward NS (2017) Restoring brain function after stroke-bridging the gap between animals and humans. Nat Rev Neurol 13:244-255

Ward NS, Brander F, Kelly K (2019) Intensive upper limb neurorehabilitation in chronic stroke: outcomes from the Queen Square programme. J Neurol Neurosurg Psychiatry 90(5):498-506. https://doi.org/10.1136/jnnp-2018-319954

Wieloch T, Nikolich K (2006) Mechanisms of neural plasticity following brain injury. Curr Opin Neurobiol 16:258-264

Winship IR, Murphy TH (2008) In vivo calcium imaging reveals functional rewiring of single somatosensory neurons after stroke. J Neurosci 28:6592-6606

Zai L et al (2009) Inosine alters gene expression and axonal projections in neurons contralateral to a cortical infarct and improves skilled use of the impaired limb. J Neurosci 29:8187-8197

Zai L et al (2011) Inosine augments the effects of a Nogo receptor blocker and of environmental enrichment to restore skilled forelimb use after stroke. J Neurosci 31:5977-5988

Zeiler SR, Krakauer JW (2013) The interaction between training and plasticity in the poststroke brain. Curr Opin Neurol 26:609-616

Zeiler SR et al (2013) Medial premotor cortex shows a reduction in inhibitory markers and mediates recovery in a mouse model of focal stroke. Stroke 44:483-489

Zeiler SR et al (2015) Paradoxical motor recovery from a first stroke after induction of a second stroke: reopening a Postischemic sensitive period. Neurorehabil Neural Repair 30:794. https:// doi.org/10.1177/1545968315624783

Open Access This chapter is licensed under the terms of the Creative Commons AttributionNonCommercial-NoDerivatives 4.0 International License (http://creativecommons.org/licenses/ by-nc-nd/4.0/), which permits any noncommercial use, sharing, distribution and reproduction in any medium or format, as long as you give appropriate credit to the original author(s) and the source, provide a link to the Creative Commons license and indicate if you modified the licensed material. You do not have permission under this license to share adapted material derived from this chapter or parts of it.

The images or other third party material in this chapter are included in the chapter's Creative Commons license, unless indicated otherwise in a credit line to the material. If material is not included in the chapter's Creative Commons license and your intended use is not permitted by statutory regulation or exceeds the permitted use, you will need to obtain permission directly from the copyright holder. 